Bull. Mater. Sci., Vol. 36, No. 1, February 2013, pp. 99-105. (c) Indian Academy of Sciences.

\title{
Laser cladding of Zr-based coating on AZ91D magnesium alloy for improvement of wear and corrosion resistance
}

\author{
KAIJIN HUANG ${ }^{1,2,3,4, *}$, XIN LIN ${ }^{2}$, CHANGSHENG XIE ${ }^{1}$ and T M YUE \\ ${ }^{1}$ State Key Laboratory of Materials Processing and Die \& Mould Technology, Huazhong University of Science and \\ Technology, Wuhan 430074, P. R. China \\ ${ }^{2}$ State Key Laboratory of Solidification Processing, Northwestern Polytechnic University, Xi' an 710072, P. R. China \\ ${ }^{3}$ Hubei Key Laboratory of Hydroelectric Machinery Design \& Maintenance, China Three Gorges University, Yichang \\ 443002, P. R. China \\ ${ }^{4}$ Department of Industrial and Systems Engineering, Hong Kong Polytechnic University, Hung Hom, Hong Kong
}

MS received 15 March 2011; revised 8 May 2012

\begin{abstract}
To improve the wear and corrosion resistance of AZ91D magnesium alloy, Zr-based coating made of $\mathrm{Zr}$ powder was fabricated on AZ91D magnesium alloy by laser cladding. The microstructure of the coating was characterized by XRD, SEM and TEM techniques. The wear resistance of the coating was evaluated under dry sliding wear test condition at room temperature. The corrosion resistance of the coating was tested in simulated body fluid. The results show that the coating mainly consists of $\mathrm{Zr}$, zirconium oxides and $\mathrm{Zr}$ aluminides. The coating exhibits excellent wear resistance due to the high microhardness of the coating. The main wear mechanism of the coating and the AZ91D sample are different, the former is abrasive wear and the latter is adhesive wear. The coating compared to AZ91D magnesium alloy exhibits good corrosion resistance because of the good corrosion resistance of $\mathrm{Zr}$, zirconium oxides and $\mathrm{Zr}$ aluminides in the coating.
\end{abstract}

Keywords. Laser cladding; AZ91D magnesium alloy; Zr-based coating; wear; corrosion; simulated body fluid.

\section{Introduction}

It is well known that metals, ceramics, polymers and their composites can serve as biomaterials. All of them have advantages and disadvantages, for example, metals used as implants have high impact strength, high resistance to wear, ductile and low biocompatibility, corrosion in physiological environment, mismatch for mechanical properties with soft connective tissue; ceramics used as implants have good biocompatibility, inert, corrosion resistance, high tensile strength and undesirable surface properties, special techniques are needed for material fabrication; polymers used as implants have low density, easy to fabricate and low mechanical strength, additives, oligomers may cause tissue reactions (Balamurugan et al 2008). Among these, metals such as stainless steels, titanium alloys and cobalt-based alloys are suitable for load-bearing applications compared with ceramics or polymers due to their combination of high mechanical strength and excellent fracture toughness. However, the conventional metallic biomaterials have a risk of releasing toxic metallic ions and/or particles through corrosion or wear process that lead to inflammatory cascades which reduce biocompatibility and cause tissue loss, and the elastic moduli of the conventional metallic biomaterials are not well matched with that of natural bone tissue, resulting in stress shielding effect that can lead to reduced stimulation of new bone

\footnotetext{
*Author for correspondence (huangkaijin@yahoo.com.cn)
}

growth and remodelling which decreases implant stability (Staiger et al 2006; Zeng et al 2008).

To improve the wear and corrosion resistance of conventional metallic biomaterials, many surface treatment processes such as shot-peening, laser shock peening, nitriding, ion implantation, passivation, electropolishing, chemical oxidation, surface nanocrystallization, protective coatings on metallic implants have been adopted (Balamurugan et al 2008; Antunes and de Oliveira 2012). However, perhaps the most versatile surface modification method is based on the deposition of protective coatings on metallic implants, and involves the improvement of a variety of material properties, such as biocompatibility, corrosion and wear resistance. For example, the effect of titanium nitride (TiN) and diamond-like carbon (DLC) coatings on the wear and corrosion properties of AISI 316L surgical stainless steel specimens were investigated by Wang et al (2010). The TiN layer was deposited using electron-beam plasma-assisted physical vapour deposition while the DLC film was produced by a plasma-assisted chemical vapour deposition method. Both coatings significantly improved the corrosion resistance and wear resistance of the substrate. Nevertheless, it is important to bear in mind that such layers have intrinsic limitations regarding their application as protective films on loadbearing implants. These include the formation of wear debris and the intrinsic brittleness of PVD thin films.

In addition, the bioceramics coating fabricated by different methods such as plasma spray technique, ion beam 
assisted deposition, magnetron sputtering, sol-gel and pulsed laser deposition, such as HAP $\left[\mathrm{Ca}_{10}\left(\mathrm{PO}_{4}\right)_{6}(\mathrm{OH})_{2}\right]$, $\mathrm{TCP}\left[\mathrm{Ca}_{3}\left(\mathrm{PO}_{4}\right)_{2}\right]$ and their bi-phase combinations can reduce the release of toxic or harmful ions from the metal alloys, because the bioceramics coating represents a truly effective barrier that hinders the metallic ion kinetics of release towards the living body (Balamurugan et al 2008). However, the poor mechanical properties of calcium phosphates limit the use of the bulk material to non-load bearing implants and are always used to coat inert or biotolerable implants with mechanical properties adequate for orthopaedic substitutions.

Searching among the existing commercially available metals and alloys, we can find that $\mathrm{Mg}$ is probably the most appropriate metal that can best fulfil the density and stiffness requirements. Although the attempt failed as the metal corroded too rapidly in vivo, interest in using $\mathrm{Mg}$ for orthopedic implants has not faded but still remains strong, especially for degradable biomaterials. The reason is that the corrosion rate of $\mathrm{Mg}$ and its alloys can be modulated through the use of high purity $\mathrm{Mg}$ or new alloying systems (Gao et al 2008; Li et al 2008; Erinc et al 2009; Gu et al 2009; Rettig and Virtanen 2009) and surface modification including protective coatings (Song 2007; Chen J et al 2008; Majumdar et al 2008; Song et al 2008; Xin et al 2008; Shi et al 2009) and surface treatments (Liu et al 2007a, b; Hanzi et al 2009; Xu et al 2009; Wen et al 2009). It is considered that if the corrosion problem of $\mathrm{Mg}$ can be resolved, $\mathrm{Mg}$ or its alloys could become good materials for implantation applications.

In the present study, an attempt has been made to fabricate $\mathrm{Zr}$-based coating made of $\mathrm{Zr}$ powder on AZ91D magnesium alloy by laser cladding. $\mathrm{Zr}$ was used because $\mathrm{Zr}$ and its oxides show excellent electrochemical properties (Gao et al 2008; Tsutsumi et al 2009), no toxicity (Akahori et al 2008; Chen X B et al 2008; Gu et al 2009) and good biocompatibility (Uchida et al 2002a, b; Shi and Hulbert 2002; Liu et al 2006; Chen X B et al 2008; Han et al 2009). It should be pointed out that although PVD, thermal spraying and plasma spraying, etc can also be used to fabricate wear and corrosion resistant coatings on $\mathrm{Mg}$, they have their disadvantages. For example, many pores and weak bonding are the main drawbacks of the coatings fabricated by thermal spraying and plasma spraying. While PVD is a line of sight technique so there are limitations on workpiece geometry, also the coating does not form a metallurgical bond with the substrate. The advantages of laser cladding can fabricate porosity free coatings with a strong metallurgically bonded coating interface. Moreover, multiple powder compositions can be fed simultaneously or sequentially to form the desired properties at specific locations.

\section{Experimental}

Laser cladding of Zr powder was conducted on AZ91D magnesium alloy. The size of specimen was $50 \times 25 \times 10 \mathrm{~mm}$. The size of the powder was $<75 \mu \mathrm{m}$ and the purity of the powder was 99 mass \%. The powder was delivered into the laser molten pool with a lateral powder feeder driven by a flow of Ar gas. Laser cladding was performed using a high power $\mathrm{PRC} \mathrm{CO}_{2}$ continuous wave laser. The laser spot diameter, laser power, powder feeding rate and laser scanning velocity were kept constant at $3 \mathrm{~mm}, 1000 \mathrm{~W}, 0.08 \mathrm{~g} / \mathrm{s}$ and $15 \mathrm{~mm} / \mathrm{s}$, respectively. A track overlap condition of $30 \%$ was used.

The different phases of the Zr-based coating were determined with the X-ray diffraction (XRD) technique using $\mathrm{CuK} \alpha$ radiation at $40 \mathrm{kV}$ and $30 \mathrm{~mA}$ ( $\mathrm{X}^{\prime}$ Pert PRO) and transmission electron microscopy (TEM, FEI Tecnai G220). The microstructure of the coating etched with an aqua regia, the surface morphologies of the worn and corrosive specimens were examined by a Quanta 200 scanning electron microscope (SEM) with energy dispersive X-ray spectroscopy (EDS). Cross-section specimens were prepared for TEM study. A microhardness tester (MICROMET 3) using a test load of $100 \mathrm{~g}$ and a load-well time of $15 \mathrm{~s}$ was employed to measure the microhardness of the coating.

Although there are some differences between the wet sliding wear under body fluid environment at human body temperature and the dry sliding wear under air environment at room temperature, the wear rate of dry sliding wear is the biggest among all different wear types under the same conditions, so the dry sliding wear resistance of the Zr-based coating was evaluated using a block-on-ring wear tester at room temperature. The cladded specimens for the wear test were cube blocks $(10 \times 10 \times 10 \mathrm{~mm})$ which were slided against a rotating ring of hardened bearing steel AISI52100 with a hardness of $60 \mathrm{HRC}$. The test load used was $98 \mathrm{~N}$. The relative sliding speed was at $0.4187 \mathrm{~m} / \mathrm{s}$. The wear test cycle lasted for $75 \mathrm{~min}$ and the corresponding total wear sliding distance was $1884 \mathrm{~m}$. The as-received AZ91D magnesium alloy was selected as the reference materials for all wear tests. Each test was repeated three times. The wear weight
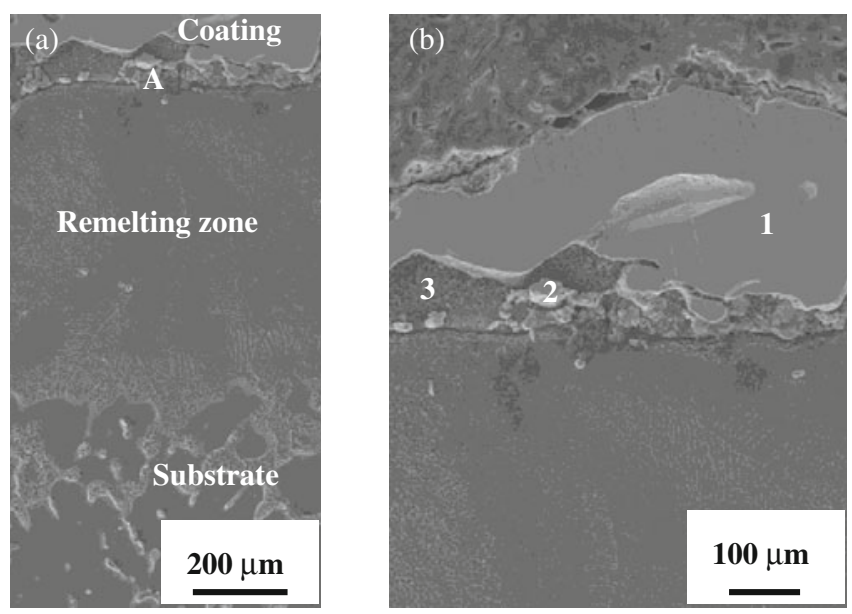

Figure 1. Microstructure of $\mathrm{Zr}$-based coating fabricated by laser cladding: (a) cross section of coating and (b) higher magnification of region $\mathrm{A}$ in figure $\mathbf{1}$ (a). 

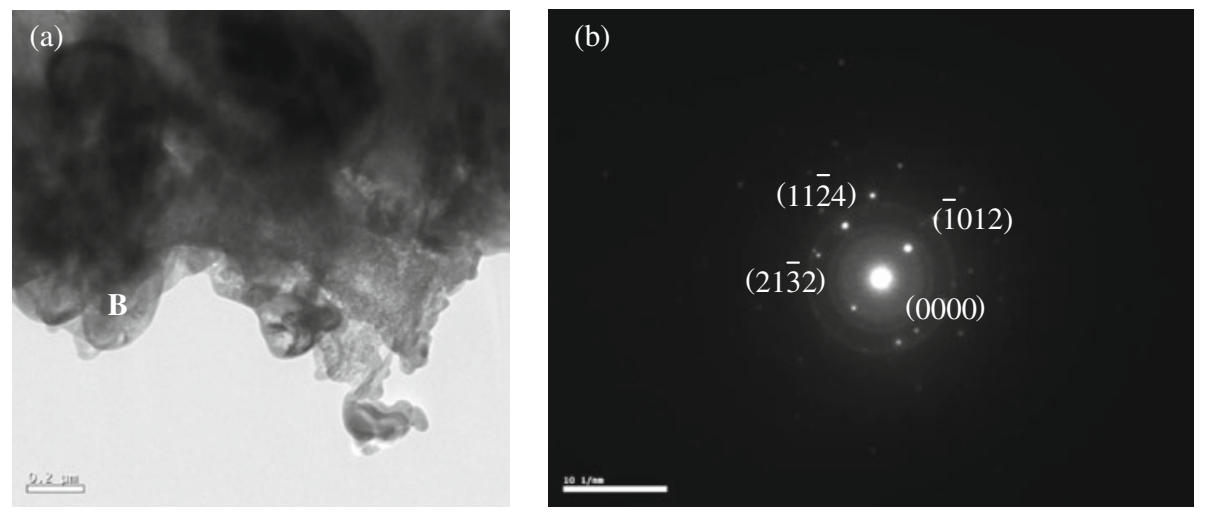

Figure 2. TEM image and SAED patterns of Zr-based coating fabricated by laser cladding: (a) Bright field image of coating and (b) diffraction pattern from [ $\overline{2} 6 \overline{1}]$ of $\mathrm{Zr}$ phase at location $\mathrm{B}$ in figure 2 (a).

Table 1. Results of EDS analysis of Zr-based coating.

\begin{tabular}{lcccc}
\hline Position & $\mathrm{Zr}$ (mass\%) & $\mathrm{Mg}$ (mass\%) & $\mathrm{Al}$ (mass\%) & $\mathrm{O}$ (mass\%) \\
\hline 1 & 72.50 & - & 23.75 & 3.75 \\
2 & 82.82 & - & 10.25 & 6.93 \\
3 & - & 82.00 & 11.70 & 6.30 \\
$\mathrm{~B}$ & 96.40 & - & 3.30 & 0.30 \\
\hline
\end{tabular}

loss was measured using an electronic balance (Bartorius BS110) with an accuracy of $0.1 \mathrm{mg}$.

The potentio-dynamic polarization test was employed to evaluate the corrosion behaviour of the Zr-based coating. The test was conducted in simulated body fluid, viz Ringer's solution $\left(8.5 \mathrm{~g} / \mathrm{L} \mathrm{NaCl}, 0.25 \mathrm{~g} / \mathrm{L} \mathrm{KCl}, 0.22 \mathrm{~g} / \mathrm{L} \mathrm{CaCl}_{2}, 0.15 \mathrm{~g} / \mathrm{L}\right.$ $\mathrm{NaHCO}_{3}$ ) at $\mathrm{pH}=7.4$ using saturated calomel electrode (SCE) as reference electrode and platinum as counter electrode. Polarization was carried out at a scan rate of $1 \mathrm{mV} / \mathrm{s}$. Before the polarization test, the specimens were kept in the Ringer's solution for $600 \mathrm{~s}$ at $37^{\circ} \mathrm{C}$.

\section{Results and discussion}

\subsection{Microstructure}

Figure 1 shows microstructure of the Zr-based coating. This figure shows three distinct zones: viz. the coating, the re-melting zone and the substrate. Figure 2 shows a TEM image of an area in the coating with the SAED pattern of $\mathrm{Zr}$ particle. Table 1 summarizes the results of the EDS analysis of the coating. Figure 3 shows XRD patterns of the coating. XRD results together with the EDS results and the TEM study suggest that the microstructure of the coating mainly consists of $\mathrm{Zr}$, $\mathrm{Zr}$ oxides and $\mathrm{Zr}$ aluminides.

During laser cladding, when the high power $\mathrm{CO}_{2}$ laser reaches the preplaced $\mathrm{Zr}$ powder coating, the $\mathrm{Zr}$ powder adsorbs $\mathrm{CO}_{2}$ laser and is heated up to the melting point of $\mathrm{Zr}(2125 \mathrm{~K})$ quickly and forms liquid $\mathrm{Zr}$. Then, since oxygen

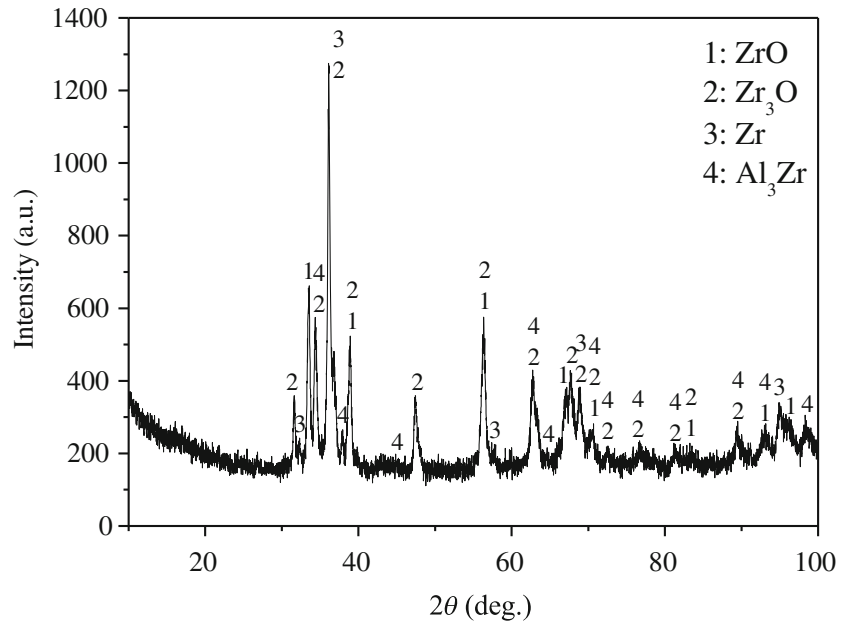

Figure 3. XRD patterns of Zr-based coating fabricated by laser cladding.

in the surrounding environment has a very high affinity to $\mathrm{Zr}$, partial liquid $\mathrm{Zr}$ will react with the dissolved oxygen and forms different $\mathrm{Zr}$ oxides according to $\mathrm{Zr}-\mathrm{O}$ phase diagram because its melting temperature is higher than that of the $\mathrm{Zr}$ and $\mathrm{Al}_{3} \mathrm{Zr}(1853 \mathrm{~K})$ phases. In succession, the unwanted liquid $\mathrm{Zr}$ will solidify when the temperature of liquid $\mathrm{Zr}$ decreases to $2125 \mathrm{~K}$. After the $\mathrm{Zr}$ oxides and $\mathrm{Zr}$ phases are formed one after another, the remaining liquid, which is rich in Al coming from the melted AZ91D substrate, will finally solidify and forms $\mathrm{Al}_{3} \mathrm{Zr}$ intermetallic compounds according to $\mathrm{Al}-\mathrm{Zr}$ phase diagram under the help of high convection velocity of the laser melt pool (Picasso and Hoadley 1994).

In addition, according to the results of the EDS analysis of the coating (table 1 ), no $\mathrm{Mg}$, but $\mathrm{Al}$ was detected in the coating. The explanation is that during laser cladding of the $\mathrm{Zr}$-based coating, the temperature of the processing zone exceeded the melting point of $\mathrm{Zr}(2125 \mathrm{~K})$, which is higher than the boiling point of $\mathrm{Mg}(1380 \mathrm{~K})$, but lower than that of Al (2740 K). Under such a condition, when $\mathrm{Zr}$ was melted, 


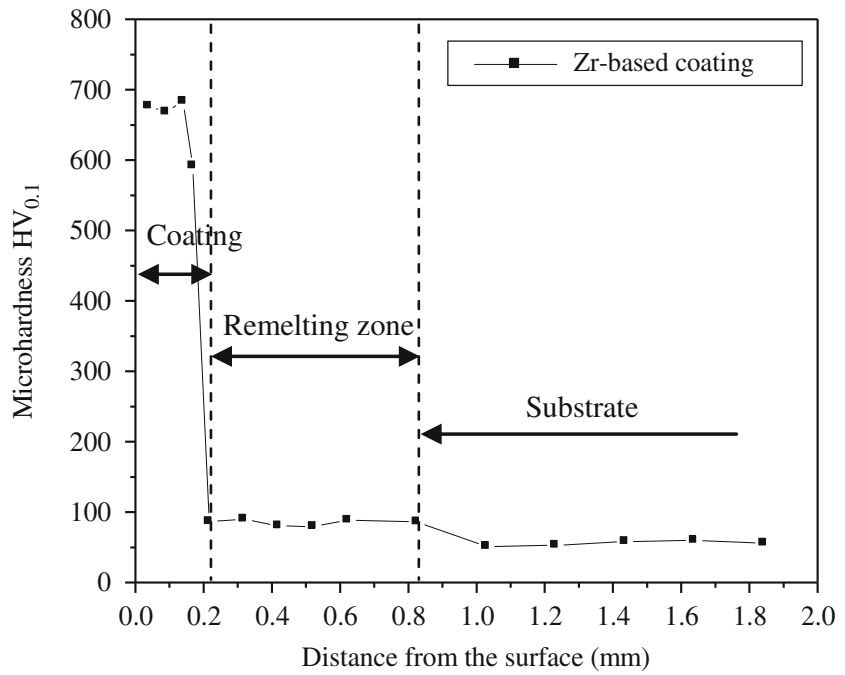

Figure 4. Microhardness of $\mathrm{Zr}$-based coating fabricated by laser cladding.

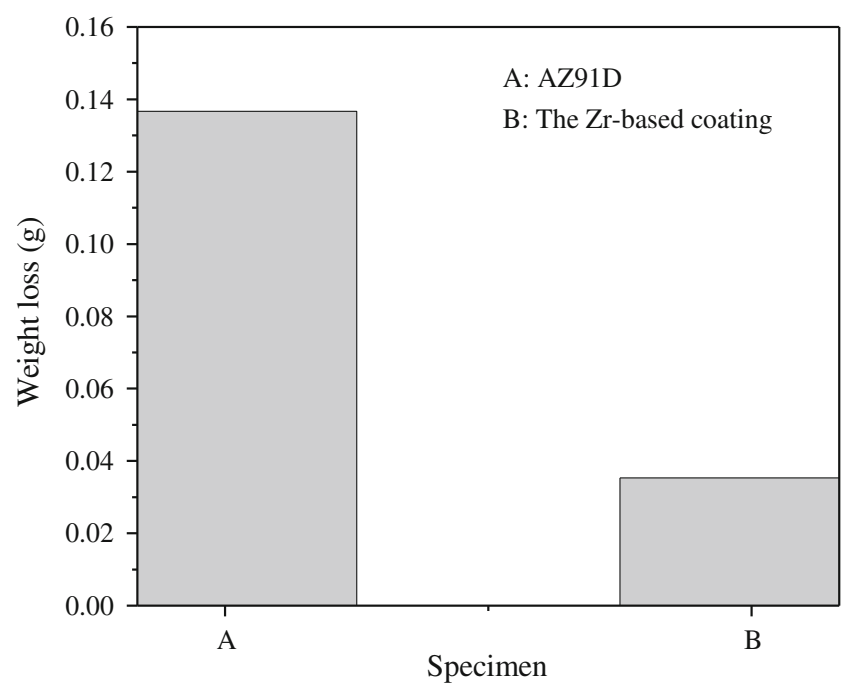

Figure 5. Weight loss of different specimens under dry wear conditions at room temperature. the surrounding $\mathrm{Mg}$ would be vapourized leaving $\mathrm{Al}$ in the melt pool to react with $\mathrm{Zr}$. The microhardness of the $\mathrm{Zr}$-based coating was very high (figure 4 ) because the coating consists of $\mathrm{Zr}$ oxides and $\mathrm{Al}_{3} \mathrm{Zr}$ phases of high hardness, and is about 6-7 times higher than that of the AZ91D substrate.

\subsection{Wear properties}

Figure 5 shows weight loss of the Zr-based coating specimen and the AZ91D material without a coating, i.e. untreated, under dry wear conditions. The weight loss of the $\mathrm{Zr}$ based coating specimen was lower than that of the untreated AZ91D specimen. In other words, the wear resistance of the Zr-based coating was obviously better than that of AZ91D specimen because the weight loss of AZ91D specimen is about 3.9 times higher than that of the Zr-based coating specimen. The wear resistance results of different specimens are consistent with the corresponding microhardnesses of different specimens (figure 4), and the higher microhardness, the better wear resistance.

The Zr-based coating mainly consists of $\mathrm{Zr}$, $\mathrm{Zr}$ oxides and $\mathrm{Zr}$ aluminides (figure 3 ). The microstructure provided the coating with an excellent wear resistance under dry wear condition, as indicated in figures 5 and 6 . As shown in figure 6, the worn surface of the untreated AZ91D specimen suffered from severe adhesive wear and the worn surface of the Zr-based coating specimen experienced severe abrasive wear. The former is evident by the feature of heavy plastic deformation (figure 6a) and the large mass wear rate $\left(3.04 \times 10^{-8} \mathrm{~kg} / \mathrm{s}\right)$. The latter is evident by the relatively mild plastic deformation but with many small particles of wear debris found at the surface (figure 6b) and the small mass wear rate $\left(7.84 \times 10^{-9} \mathrm{~kg} / \mathrm{s}\right)$. The results of the EDS analysis showed that these particles were mainly composed of iron oxides (table 2). Apparently, the above characteristics of the worn surfaces are related to the surface microhardness of different specimens.

It is indicated that under the condition of room temperature dry sliding wear test, the surface of an untreated
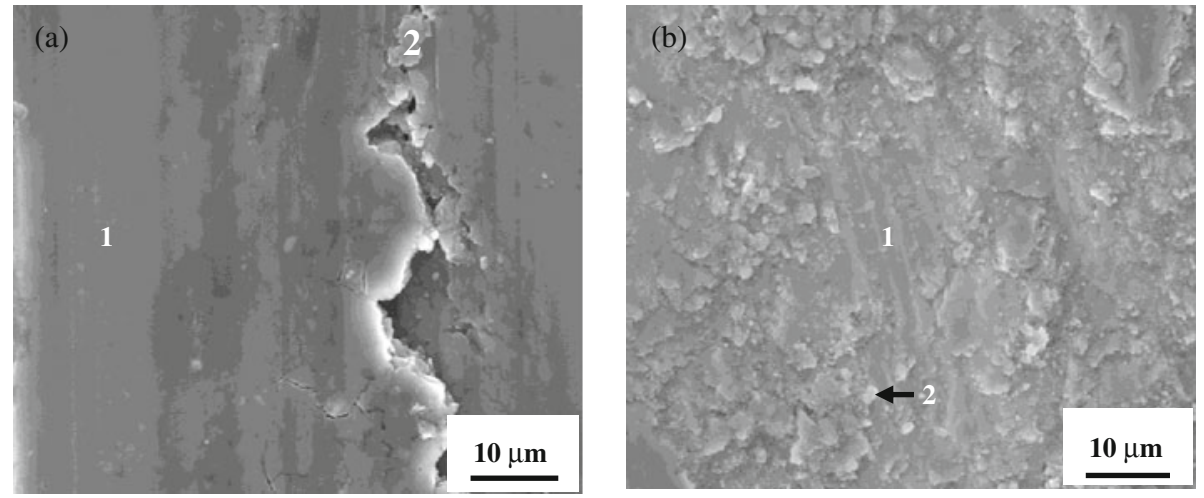

Figure 6. SEM images of worn surfaces of different specimens: (a) untreated specimen AZ91D and (b) Zr-based coating specimen. 
Table 2. EDS results of worn surface (mass\%).

\begin{tabular}{lccrrrrrrr}
\hline Sample & Position & $\mathrm{C}$ & $\mathrm{O}$ & $\mathrm{Mg}$ & $\mathrm{Al}$ & $\mathrm{Zn}$ & $\mathrm{Fe}$ & $\mathrm{Zr}$ & $\mathrm{Mn}$ \\
\hline AZ91D & 1 & 2.86 & 8.64 & 82.18 & 5.68 & 0.64 & - & - & - \\
AZ91D & 2 & 2.08 & 14.86 & 77.52 & 4.36 & 0.72 & 0.46 & - & - \\
Zr-based coating & 1 & 1.08 & 6.42 & 1.38 & 6.46 & - & 13.70 & 70.96 & - \\
Zr-based coating & 2 & 1.02 & 38.40 & 0.30 & 0.40 & - & $59 \cdot 20$ & 0.68 & - \\
AZ91D & Raw & - & - & 90.16 & 8.95 & 0.63 & - & - & 0.26 \\
\hline
\end{tabular}

specimen AZ91D would first adhere to the surface of the hardened AISI52100 steel ring and then smeared off because of its low hardness of the untreated specimen AZ91D (figure 4). On the other hand, the worn surface of the $\mathrm{Zr}$ based coating was covered with wear debris particles including iron oxides (figure $6 \mathrm{~b}$ and table 2). Such results were not observed on the untreated AZ91D sample.

In normal sliding tests, there is a material-to-material contact, followed by welding or fusing of the contacting asperities. When sliding continues, the asperities of the weaker material may shear off and transfer to the opposite surface (Kelly et al 1998). In the present work, in case of the untreated specimen AZ91D, the hardened AISI52100 steel ring, whose main constituent is $\mathrm{Fe}$, shears the soft magnesium phase off; as a result, small content of iron is deposited on the worn surface (table 2). On the contrary, the microhardness of the Zr-based coating (figure 4) is almost the same as the hardened AISI52100 steel ring, and the material from the ring is sheared off, as a result, large content of iron is deposited on the worn surface (table 2). At the same time, the $\mathrm{Zr}$, $\mathrm{Zr}$ oxides and $\mathrm{Zr}$ aluminides would be broken up by the dry sliding action and smeared along the surface.

In conclusion, according to the morphologies of the worn surfaces (figure 6) and the results of EDS (table 2), the dominant type of wear mechanism of the relatively soft untreated AZ91D is considered to be adhesive wear process. On the other hand, the type of wear mechanism of the Zr-based coating specimen is dominated by abrasive wear process. Nevertheless, oxidation and friction wear might also be involved in cases of the untreated specimen AZ91D and the Zr-based coating specimen.

\subsection{Corrosion properties}

Figure 7 shows potentio-dynamic polarization curves of different specimens. Table 3 lists the corrosion parameters of different specimens in Ringer's solution. The results show that the Zr-based coating is superior to the untreated AZ91D substrate in corrosion properties. For example, the corresponding corrosion potential ( $E_{\text {corr }}$ ) of the Zr-based coating specimen is $-0.4425 \mathrm{~V}$, which is $928.1 \mathrm{mV}$ more positive than the corrosion potential of the untreated AZ91D substrate. The open-circuit corrosion current density $\left(I_{\text {corr }}\right)$ of the untreated AZ91D substrate is about 923.4 times higher than that of the $\mathrm{Zr}$-based coating. The corresponding polarized resistance $\left(R_{\mathrm{p}}\right)$ of the $\mathrm{Zr}$-based coating is about 351.7

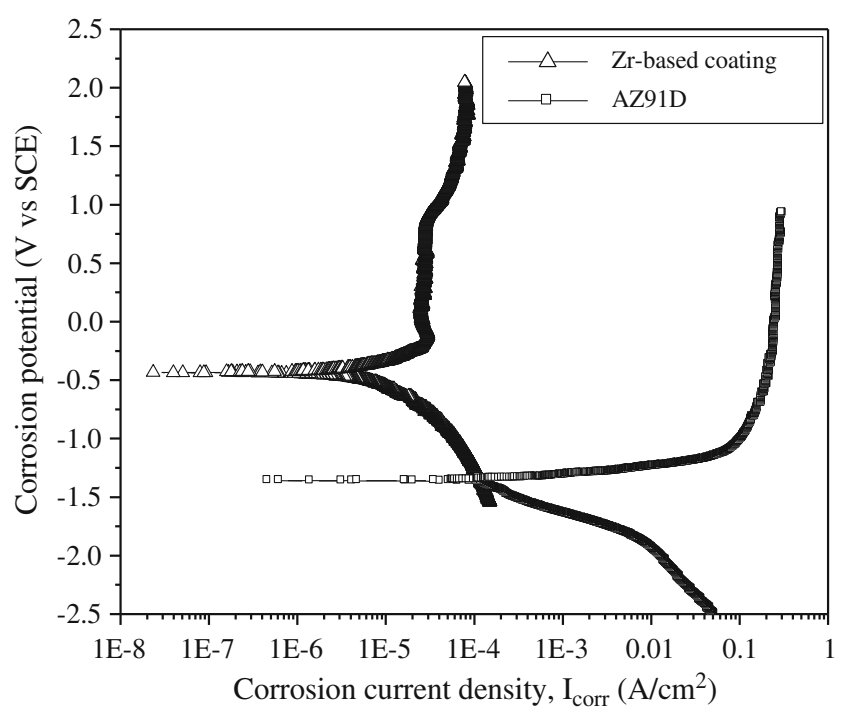

Figure 7. Potentiodynamic polarization curves of different specimens in Ringer's solution.

times higher than that of the untreated AZ91D substrate. The corrosion rate (CR) of the untreated AZ91D substrate is about 228.1 times higher than that of the Zr-based coating. Figure 8 shows SEM morphologies of corrosive surfaces of different specimens.

For AZ91D magnesium alloy, the mass fraction of $\mathrm{Mg}$ is about 90 mass\% (table 2). $\mathrm{Mg}$ is a very active metal, the equilibrium potential of $\mathrm{Mg}$ is $-2.37 \mathrm{~V}$ and the equilibrium potential in conventional media is also very low. Moreover, the oxide film of magnesium is generally loose and porous; therefore, AZ91D magnesium alloy normally has fairly poor corrosion resistance. The electrochemical corrosion of AZ91D magnesium alloy is mainly the process of releasing hydrogen with its quick dissolution.

According to a modified $\mathrm{pH}$-potential diagram of $\mathrm{Mg}$ and its alloys in various simulated body fluids, the corrosion attack of magnesium in an aqueous environment can be expressed as the following partial reactions (Zeng et al 2008):

$$
\begin{aligned}
& \text { Anodic reaction: } \mathrm{Mg} \rightarrow \mathrm{Mg}^{2+}+2 e, \\
& \text { Cathodic reaction: } 2 \mathrm{H}_{2} \mathrm{O}+2 e \rightarrow 2 \mathrm{OH}^{-}+\mathrm{H}_{2}, \\
& \text { Production formation: } \mathrm{Mg}^{2+}+2 \mathrm{OH}^{-} \rightarrow \mathrm{Mg}(\mathrm{OH})_{2} \text {, } \\
& \text { General reaction: } \mathrm{Mg}+2 \mathrm{H}_{2} \mathrm{O} \rightarrow \mathrm{Mg}(\mathrm{OH})_{2}+\mathrm{H}_{2} \text {. }
\end{aligned}
$$


Table 3. Corrosion parameters of different specimens in Ringer's solution.

\begin{tabular}{lllcc}
\hline Specimen & $E_{\text {corr }}(\mathrm{V})$ & $I_{\text {corr }}\left(\mathrm{A} / \mathrm{cm}^{2}\right)$ & $R_{\mathrm{p}}\left(\Omega / \mathrm{cm}^{2}\right)$ & CR (mm/year) \\
\hline AZ91D & -1.3706 & 0.0008971 & 29.079 & 14.697 \\
Zr-based coating & -0.4425 & 0.000009175 & 10228 & 0.06442 \\
\hline
\end{tabular}
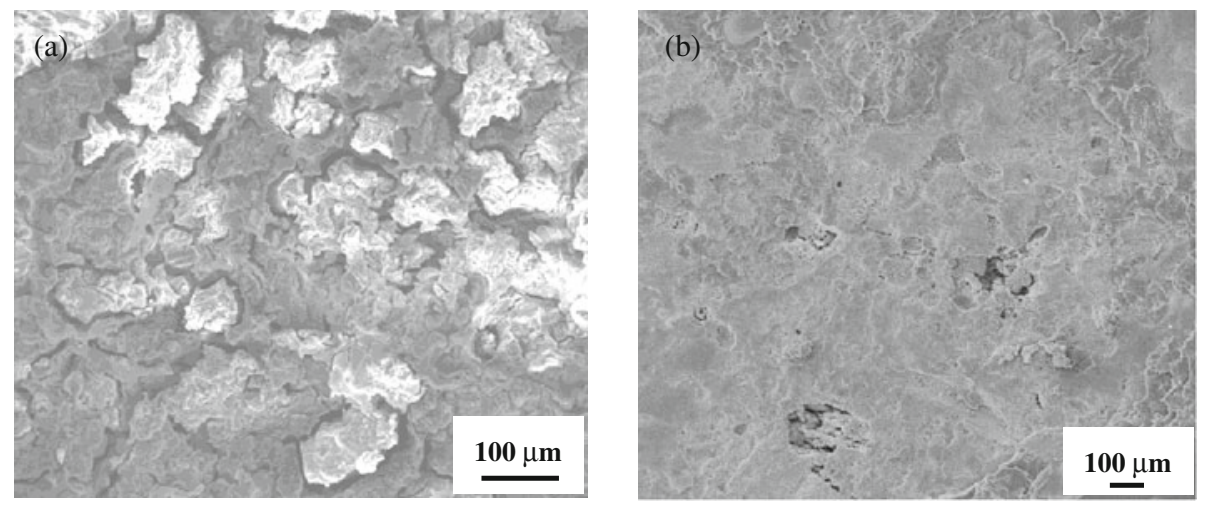

Figure 8. SEM images of corroded surfaces of different specimens: (a) untreated specimen AZ91D and (b) Zr-based coating specimen.

Therefore, the dissolution of $\mathrm{Mg}$ in simulated body fluid goes with the release of $\mathrm{H}_{2}$. This can be proved by the phenomena that many gas bubbles produced when the untreated specimen AZ91D was put in the simulated body fluid. It should be pointed out that the amount of gas bubbles decreased with the increase of time, and this explained the decrease of the dissolution of $\mathrm{Mg}$ in simulated body fluid because the production of $\mathrm{OH}^{-}$ion resulted in the increase of $\mathrm{pH}$ of simulated body fluid from $\mathrm{pH}=7.4$ to $\mathrm{pH}=10.5$ in the end. On the other hand, $\mathrm{Cl}^{-}$ions in simulated body fluid can destroy the grayoxide film of $\mathrm{Mg}(\mathrm{OH})_{2}$ and reacts with $\mathrm{Mg}$. The following reactions summarize the corrosion reactions of $\mathrm{Mg}$ (Staiger et al 2006):

$$
\begin{aligned}
& \mathrm{Mg}(s)+2 \mathrm{H}_{2} \mathrm{O} \rightarrow \mathrm{Mg}(\mathrm{OH})_{2}(s)+\mathrm{H}_{2}(g), \\
& \mathrm{Mg}(\mathrm{OH})_{2}(s)+2 \mathrm{Cl}^{-} \rightarrow \mathrm{MgCl}_{2}+2 \mathrm{OH}^{-}, \\
& \mathrm{Mg}(s)+\mathrm{Cl}^{-} \text {(aq.) } \rightarrow \mathrm{MgCl}_{2} .
\end{aligned}
$$

So, the corrosion of AZ91D magnesium alloy is severe (table 3 and figure 8(a)).

The relatively better corrosion property of the $\mathrm{Zr}$-based coating compared with the untreated AZ91D substrate is related to the presence of excellent corrosion resistance of Zr (Subramanian et al 1991; Gao et al 2008; Tsutsumi et al 2009), Zr oxides (Balamurugan et al 2003; Namgung et al 2010) and Zr aluminides (Nguyen-Manh and Pettifor 1999). This can be proved by the phenomena that there was no obvious microstructure morphology in the coating etched with an aqua regia (figure 1). Of course, microgalvanic corrosion also exists in the Zr-based coating due to different crystalline phases and a small quantity of corrosion products are kept on the corrosive surface (figure 8(b)).

\section{Conclusions}

Based on $\mathrm{Zr}$ powder, a high wear and corrosion resistant Zr-based coating has been successfully fabricated by laser cladding on AZ91D magnesium alloy. The Zr-based coating is mainly composed of $\mathrm{Zr}$, $\mathrm{Zr}$ oxides and $\mathrm{Al}_{3} \mathrm{Zr}$ phases. Under the dry sliding wear condition at room temperature, the wear resistance of the Zr-based coating was considerably higher than that of the untreated AZ91D material, and the weight loss of the AZ91D substrate was about 3.9 times higher than that of the Zr-based coating. The main wear mechanisms of the coating and the AZ91D sample are different, the former was abrasive wear and the latter was adhesive wear. The $\mathrm{Zr}$ based coating has superior corrosion resistance when compared to the untreated AZ91D material in the simulated body fluid. The corrosion rate (CR) of the untreated AZ91D material was about 228.1 times higher than that of the Zr-based coating.

\section{Acknowledgements}

This work was supported by the Fund (SKLSP201108) of the State Key Laboratory of Solidification Processing in NWPU, the Fund (2010-P07) of the State Key Laboratory of Materials Processing and Die \& Mould Technology in HUST, 
the Foundation (2008007) of Key Laboratory for Advanced Materials Processing Technology in Tsinghua University, and the Fund (2010KJX01) of the Hubei Key Laboratory of Hydroelectric Machinery Design \& Maintenance in China Three Gorges University. The authors are also grateful to Analytical and Testing Centre of Huazhong University of Science and Technology.

\section{References}

Akahori T, Niinomi M, Nakai M, Kasuga T and Ogawa M 2008 Mater. Trans. 49365

Antunes R A and de Oliveira M C L 2012 Acta Biomater. 8937

Balamurugan A, Kannan S and Rajeswari S 2003 Mater. Lett. 574202

Balamurugan A, Rajeswari S, Balossier G, Rebelo A H S and Ferreira J M F 2008 Mater. Corros. 59855

Chen J, Zeng R C, Huang W J, Zheng Z Q, Wang Z L and Wang J 2008 Trans. Nonferrous Met. Soc. China 18 S361

Chen X B, Nouri A, Li Y C, Lin J G, Hodgson P D and Wen C 2008 Biotechnol. Bioeng. 101378

Erinc M, Sillekens W H, Mannens R G T M and Werkhoven R J 2009 Applicability of existing magnesium alloys as biomedical implant materials. in Proceeding (eds) E A Nyberg et al (New York: TMS) p. 209

Gao J C, Wu S, Qiao L Y and Wang Y 2008 Trans. Nonferrous Met. Soc. China 18588

Gu X N, Zheng Y F, Cheng Y, Zhong S P and Xi T F 2009 Biomaterials 30484

Han Y, Yan Y Y, Liu G G, Zhang Y M and Xu K M 2009 J. Biomed. Mater. Res. A88 117

Hanzi A C, Gunde P, Schinhammer M and Uggowitzer P J 2009 Acta Biomater. 5162

Kelly J, Nagarathnam K and Mazumder J 1998 J. Laser Appl. 1045

Li Z J, Gu X N, Lou S Q and Zheng Y F 2008 Biomaterials 291329
Liu X Y, Huang A P, Ding C X and Chu P K 2006 Biomaterials 27 3904

Liu C L, Xin Y C, Tang G Y and Chu P K 2007a Mater. Sci. Eng. A 456350

Liu C L, Xin Y C, Tian X B, Zhao J and Chu P K 2007b J. Vac. Sci. Technol. A 25334

Majumdar J D, Bhattacharyya U, Biswas A and Manna I 2008 Surf. Coat. Technol. 2023638

Namgung S, Ko Y G, Shin K R and Shin D H 2010 Korean J. Met. Mater. 48813

Nguyen-Manh D and Pettifor D G 1999 Intermetallics 71095

Picasso M and Hoadley A F A 1994 Int. J. Numer. Meth. Heat Fluid Flow 461

Rettig R and Virtanen S 2009 J. Biomed. Mater. Res. A88 359

Shi P, Ng W F, Wong M H and Cheng F T 2009 J. Alloys Compds. 469286

Shi X F and Hulbert S 2002 Biomed. Sci. Instrum. 38489

Song G L 2007 Adv. Mater. Res. 2995

Song Y W, Shan D Y and Han E H 2008 Mater. Lett. 623276

Staiger M P, Pietak A M, Huadmai J and Dias G 2006 Biomaterials 271728

Subramanian R, Sircar S and Mazumder J 1991 J. Mater. Sci. 26951

Tsutsumi Y, Nishimura D, Doi H, Nomura N and Hanawa T 2009 Mater. Sci. Eng. C 291702

Uchida M, Kim H M, Miyaji F, Kokubo T and Nakamura T 2002a Biomaterials 23313

Uchida M, Kim H M, Kokubo T, Tanaka K and Nakamura T 2002b J. Ceram. Soc. Jpn 110710

Wang L, Su J F and Nie X 2010 Surf. Coat. Technol. 2051599

Wen C L, Guan S K, Peng L, Ren C X, Wang X and Hu Z H 2009 Appl. Surf. Sci. 2556433

Xin Y C, Liu C L, Zhang W J, Jiang J, Tang G Y, Tian X B and Chu P K 2008 J. Electrochem. Soc. 155 C178

Xu L P, Zhang E L and Yang K 2009 J. Mater. Sci.: Mater. Med. 20859

Zeng R C, Dietzel W, Witte F, Hort N and Blawert C 2008 Adv. Biomater. $10 \mathrm{~B} 3$ 